\title{
LA DIMENSIÓN PRÁCTICA DE LA FILOSOFÍA SEGÚN JUAN DE SALISBURY
}

\author{
César Raña Dafonte \\ Universidad de Santiago de Compostela
}

\section{RESUMEN}

Este trabajo presenta la filosofía práctica según Juan de Salisbury, concretada en sus reflexiones sobre ética, filosofía política, actividad docente y tarea de escritor.

Palabras clave: Juan de Salisbury, filosofía práctica, ética, política, docencia, escritura.

\section{ABSTRACT}

This paper presents the Practical Philosophy according to John of Salisbury, as it is found in his reflections about Ethics, Political Philosophy, teaching activity and his production as a writer.

Key words: John of Salisbury, Practical Philosophy, Ethics, Politics, Teaching, Writing.

«Est enim quaelibet professio philosophandi inutilis et falsa, quae se ipsam in cultu virtutis et vitae exhibitione non aperit» (Metalogicon, Prologus)

Los escritos y el pensamiento de Juan de Salisbury (1110/20-1180) ponen de manifiesto que estamos ante un autor importante para conocer la vida y las actividades culturales fundamentales del siglo XII. Fue un clérigo secular, excepcional testigo de la actividad político-eclesiástica de su época en Inglaterra, Francia y la Curia Romana. Su profesión se centra en la actividad diplomática y en la administración de asuntos eclesiásticos. Muere en 1180, siendo obispo de Chartres. Ahora bien, sus múltiples actividades no fueron óbice para una intensa tarea de escritor, que dará lugar a obras del mayor interés literario e informativo. Incluso tiene una vena poética muy notable: la ponen de manifiesto el Entético, y una breve, pero muy bella composición sobre los miembros corpóreos y su mutua colaboración (De membris conspirantibus). De todas formas, es sabido, que sus obras cumbres son el Policraticus y el Metalogicon ${ }^{1}$.

Nuestro autor subraya que la filosofía es la búsqueda racional de la verdad, por ello advierte que «no es auténtico filósofo el que elige más por gusto que por razón aquello que va a seguir» ${ }^{2}$. También recuerda que la verdadera filosofía supone esfuerzo, estudio; por ello critica a los que «imitan más a los peripatéticos en el paseo y dar vueltas por las calles, que en la investigación

1 Para una visión de conjunto sobre el autor, cfr. mi libro Juan de Salisbury (1110/20-1180), Madrid, Ediciones del Orto, 1999.

2 Policraticus, VII, 9, p. 524; PL, 199, 653D (Utilizo la traducción castellana preparada por M.A. Ladero, Editora Nacional, Madrid, 1983. En adelante para referirme a esta obra uso la sigla P. También señalo (para texto latino) la paginación de J.P. Migne, Patología Latina. 
diligente de las cosas» ${ }^{3}$. Asimismo menciona el método adecuado para la filosofía: «Para el ejercicio de toda filosofía son medios indispensables: la lectura, la asimilación de la doctrina y la reflexión, todo esto unido a una investigación constante» ${ }^{4}$. Distingue con nitidez entre filosofía teórica y práctica. Prescindo totalmente de la presentación de la filosofía teórica, y me centro exclusivamente en la práctica, según el objetivo propuesto en el título del trabajo.

El propio autor nos informa de su convicción íntima hacia la filosofía práctica: «Introduje conscientemente unas consideraciones sobre la praxis, persuadido de que todo lo que se escribe o lee resulta inútil, a no ser que nos oriente en nuestra vida. En efecto, considero vana la actividad filosófica, incluso falsa, si no incide en la vidạ para hacerla más digna» («De moribus vero non nulla scienter inserui, ratus omnia quae leguntur aut scribuntur inutilia esse nisi quatenus afferunt aliquod adminiculum vitae. Est enim quaelibet professio philosophandi inutilis et falsa, quae se ipsam in cultu virtutis et vitae exhibitione non aperit») ${ }^{5}$. Dado este talante, resulta muy coherente que la presentación de la parte práctica de la filosofía sea mucho más amplia que la referente a la filosofía teórica (especialmente lo relativo a la filosofía política). La obra fundamental para esta faceta es, sin duda, el Policraticus.

\section{LA FILOSOFÍA MORAL}

De una lectura atenta de Policraticus se desprende con claridad que la preocupación ética está presente a lo largo de toda la obra. Desde las primeras páginas hasta las últimas emerge constantemente. Por supuesto, no es algo insólito en autores del siglo XII. Sirva como ejemplo muy significativo la actitud de Pedro Abelardo (estrella intelectual de la primera mita del siglo) que, refiriéndose a la ética, afirma expresamente: «Me dirigí finalmente a la filosofía moral, que es el objetivo final de las restantes disciplinas y respecto a la cual éstas no son sino sabrosas primicias» ${ }^{6}$. Es más que probable que las aportaciones de Abelardo las hubiese escuchado Juan, más de una vez, de labios del gran maestro.

Aunque no hay un tratamiento ordenado y sistemático de la ética en general, sí que se pueden espigar insinuaciones sumamente interesantes.

Ante todo, y en consonancia con la conciencia creciente del peso del individuo en el ambiente del siglo XII, aparece subrayada la importancia esencial de la intención, como fundamento del valor moral de las acciones: «También la causa de un acto puede ennoblecerlo, si resulta necesario, útil u honesto, ya que la intención marca la calidad de la acción [...]. Porque una acción no constituye crimen por sí misma, sino por la causa que la mueve» ${ }^{7}$. En otros pasajes insiste en su ética de la intención o buena voluntad como base para la bondad de las acciones humanas: «Se deja de realizar, ciertamente, lo que no se lleva a cabo ni con las palabras ni con la voluntad. Porque lo que quieres hacer y no puedes, Dios lo da por hecho. Ya que la verdadera voluntad de hacer algo consigue la recompensa de la obra realizada» ${ }^{8}$. Y un poco más adelante escribe: «Verdaderamente, no pienso que debamos esperar que dé consejos quien no cometió pecado sino el que no considera provechoso pecar, el que odie el pecado, se alegre en la virtud y la apetezca con vehemente deseo, es decir, el hombre de buena voluntad» ${ }^{9}$.

3 P, VII, 12, p, 538; PL, 199, 663A.

4 Metalogicon, I, 23; PL, 199, 853A (Para esta obra utilizo la edición de J. P. Migne, Patología Latina (en adelante PL), vol. 199, según la reimpresión de Brepols, Turnhout [Belgium], 1980. La sigla en adelante para $M e$ talogicon es $M$. La traducción al castellano es mía.

5 M, Prólogo, PL, 199, 825B.

6 Abelardo, P., Diálogo entre un Filósofo, un Judio y un Cristiano, Zaragoza, Yalde, 1988, p. 84.

$7 \quad$ P, I, 4, p. 119; PL, 199, 397 B, D.

$8 \quad$ P, V, 9, p. 381; PL, 199, 561 D-562A.

9 P, V, 9; p.382; 199; 562B. 
Estas insinuaciones de nuestro autor son bien elocuentes, e indican la renovación e interiorización de la moral en estos momentos de la Edad Media, en contraposición al mero moralismo externo, de aplicación general, y que era de gran difusión en momentos anteriores, y aun en pleno siglo XII. En esto se une a la visión mucho más sistematizada que Pedro Abelardo desarrolla en su Ética, y que había motivado enconadas disputas con Bernardo de Claraval, entre otros.

Aunque estamos en el ámbito de una moral religiosa, no faltan algunos rasgos que hacen a nuestro autor armonizar con una visión ética meramente filosófica, en cuanto afirma: «Todos llevamos en el corazón una especie de libro con cuanto interesa saber, que se hace patente con el recto uso de la razón. En él está delineada la fisonomía de las cosas visibles y su belleza, y, por añadidura, está grabada en él la contextura de lo invisible por el dedo de Dios. Y todo ello hasta el punto de que los que han recibido el conocimiento de sus deberes ya sea por naturaleza o por gracia, no podrán alegar ignorancia, en descargo propio» ${ }^{10}$. Y en otro lugar remacha: «Aquellos a quienes complacen las cosas buenas, no miran quién habla, sino qué es lo que dice, $y$, ponderando lo dicho por los motivos por los que se habla, agradecen todo lo que sirva, sea donde sea, con tal de que sirva para la virtud» ${ }^{11}$. Finalizamos estos testimonios de Juan con tintes tan ecuménicos con las siguientes palabras:

«Yo no estimo a los hombres por su riqueza, sino por sus costumbres. Cada uno se educa a sí mismo, el estado social lo da la suerte. Del mismo modo que es un necio el que al comprar un caballo no examina más que la manta y los frenos, resulta ser mucho más necio quien piensa que hay que estimar a los hombres por su vestido o por su condición social» ${ }^{12}$. Estas afirmaciones resultan claramente reveladoras del nuevo horizonte mental que se está fraguando en la revalorización del individuo (de la persona humana) en el mundo medieval.

\section{LA FILOSOFÍA POLÍTICA}

Sin duda el tema dominante de la obra Policraticus, y que de algún modo sirve de hilo conductor a todo el libro, es la preocupación por la vida social, y de modo especial la orientación ética de las personas que ocupan cargos de responsabilidad rectora en la sociedad. El subtítulo del Policraticus ya lo señala, de algún modo: «frivolidades de los cortesanos y enseñanzas de los filósofos» («De nugis curialium et vestigiis philosophorum»). Teniendo en cuenta estos dos aspectos del subtítulo, podemos dividir esta amplísima obra en dos grandes apartados, el primero se centra, principalmente, en la crítica de los vicios y abusos de los que rigen en la sociedad; el segundo presenta las orientaciones que Juan considera adecuadas para el buen príncipe o gobernante. Por supuesto que con motivo de las prolijas exposiciones sobre estos temas se hace alusión a otras muchas cosas que resultan muy ilustrativas de la época que le tocó vivir a nuestro autor.

\section{Parte crítica}

La presentación de los vicios y frivolidades de los cortesanos es bastante minuciosa. Siguiendo el orden del autor, la caza es la primera tentación que puede perjudicar al administrador de la cosa pública. Recojo tan sólo las palabras conclusivas sobre esta hipotética frivolidad: «Para que no parezca, con todo, que mi pluma persigue a la caza y demás frivolidades

10 P, III, 2, p. 248; PL, 199, 479A.

11 P, VIII, Prólogo, p. 612; PL, 199, 710C.

12 P, VIII, 12, p. 683; PL, 199, 757A. 
de los cortesanos con odio más que con sereno juicio, admito fácilmente con gusto que es cosa que podría considerarse indiferente, si no fuera porque con la búsqueda inmoderada del placer hace tambalearse la fortaleza del espíritu y desvía la razón [...]. Puede, por tanto, el arte de la caza ser útil y honesto, pero ello depende del lugar, tiempo, modo, persona y causa [...]. ¿Qué tenemos que ver tu y yo con la profesión de cazador? Es gran error descuidar lo propio e interesante por lo ajeno. ¿Qué le va a quien luce las insignias de la autoridad pública en una afición privada, por no decir rústica? [...] ¿No piensas que resulta indigno que el cazador aspire a la realeza o al pontificado? Más indigno todavía es, en verdad, dejarse caer desde cualquiera de ambas cúspides en las carnicerías o inmundicias del cazador» ${ }^{13}$. Después de presentar la caza como la primera posible causa de desvío del cumplimiento del deber público, hace alusión a otras varias: «Atención. Mientras se aleja el tumulto de los cazadores, otras frivolidades, aunque menos ruidosas, dejan oír sus voces» ${ }^{14}$.

Señala entre otros vicios frecuentes el juego: « No te parece necio el jugador que perece (más que vive) por obra y gracia de los dados y constituye cada tirada en árbitro de su destino? [...]. Ciertamente el juego de azar encierra mentiras y perjurios, su pasión busca lo ajeno, $y$, sin ningún respeto por el propio patrimonio, cuando lo ha dilapidado, desemboca paulatinamente en robos y rapiñas $\rangle^{15}$. También en este caso considera nuestro autor que en ciertas circunstancias el juego es cosa lícita. A continuación aparece la música como otra posible tentación, pero antes hace una presentación de los muchos aspectos positivos de la misma ${ }^{16}$. Sigue relatando otras frivolidades, entre las que cabe señalar la ociosidad y pereza. Sobre ellas advierte: «Es un consejo de hombre eruditísimo que el demonio te encuentre siempre ocupado, para que puedas oponer a sus tentaciones, con éxito y prudencia, el escudo de tus ocupaciones ${ }^{17}$. También describe y critica la magia y la astrología. Después de relatar la futileza de la magia y astrología negativas, escribe con rotundidad: «De hecho, no hay nada cuyo origen no se deba a alguna causa legítima [...]. Consta que nada escapa a la mano de la naturaleza constructora. Consecuentemente, todo pertenece a la Física» ${ }^{18}$. Estas palabras son bien significativas del nuevo sesgo del saber científico-natural en el siglo XII.

De todas formas, entre los grandes vicios de los que han de precaverse los que se dedican a la vida pública, tienen especial relevancia la adulación, la seducción de las riquezas y el amiguismo. Condena con toda energía a los que inciden en tales vicios. En cuanto al adulador, son vivísimas las descripciones que hace, y lo condena sin paliativos: «El que, hablando con propiedad, es llamado adulador con legítimo nombre, blanquea los defectos de cualquiera; y para que no se vea a sí mismo, obnubila los ojos de su contertulio con cualquier nube de vanidad, y alienta los oídos con falsos títulos de alabanza» ${ }^{19}$. Después de esta alusión esquemática a la parte crítica, he de decir que lo más novedoso e interesante del Policraticus está constituido pro la filosofía política que aporta el pensador inglés.

\section{Parte positiva}

La filosofía política del saresberiense está desarrollada, principalmente, en los libros cuarto, quinto y sexto del Policraticus. Sobre él, escribe M. A. Ladero: «Es el primer gran tratado medieval, complejo y minucioso, sobre filosofía política, redactado bajo la doble influencia de

13 P, I, 4, pp. 118-119; PL, 199, 396D-397A.

14 P, I, 5, p. 121; PL, 199, 398D.

15 P, I, 5, pp. 122-123; PL, 199, 399A, C.

16 Cfr. P, I, 6, pp. 126-127; PL, 199, 401D-402D.

17 P, I, 8, p. 132; PL, 199, 405D.

18 P, II, 1, p. 150; PL, 199, 415D.

19. P, III, 4, p. 255; PL, 199, 482D-483A. 
los pensadores altomedievales y de las autoridades latinas ${ }^{20}$. La visión de nuestro autor tiene dos grandes apoyaturas, la primera es la Biblia (como no podía ser de otro modo), en concreto el Deuteronomio; y la otra base son los grandes retóricos y éticos latinos (esto es lo más novedoso en estos momentos).

La vida colectiva o social. El autor describe la vida social acudiendo al símil del cuerpo y sus diferentes partes; cada una de ellas cumple su misión en armonía y colaboración con las demás. De la misma manera los hombres deben actuar cada uno en su propio campo, considerando el interés de la comunidad, además del suyo propio. El famoso símil está expresado del siguiente modo: «La comunidad política («res publica») es algo así como un cuerpo [...]. Todo aquello que nos instruye y forma en el culto de Dios [...], hace las veces de alma de este cuerpo de la comunidad política [...]. El príncipe ocupa en la comunidad el lugar de la cabeza y se halla sujeto solamente a Dios y a quienes en nombre de Él hacen sus veces en la tierra, como en el cuerpo humano la misma cabeza tiene vida y es gobernada por el alma. El Senado ocupa el lugar del corazón [...]. Los jueces y los gobernadores de las provincias reclaman para sí la misión de los ojos, los oídos y la lengua. Los oficiales y soldados se corresponden con las manos. Los que asisten al príncipe de modo estable, se asemejan a los costados. Los recaudadores e inspectores [...] pueden ser comparados al vientre y los intestinos [...]. Los agricultores se parecen a los pies, que se encuentran continuamente pegados al suelo» ${ }^{21}$. El pensamiento político de Juan aspira a una ideal concordia entre el interés individual y el interés de la colectividad. Para recalcar esta idea acude a otro símil bellísimo que recoge, y asume, de los clásicos: la vida colectiva de las abejas ${ }^{22}$. «Todo este cuadro ideal de la vida social y política se relaciona con el enfoque de Juan frente a la más debatida cuestión de la historia política del Medievo: las relaciones entre la autoridad temporal y la espiritual ${ }^{23}$.

Al no poder detenernos en otros grandes temas desarrollados por nuestro pensador, los citaremos, al menos, destacando algunos rasgos.

El oficio regio: el príncipe y su antítesis, el tirano. El cumplimiento o no de la ley es el signo distintivo del príncipe y del tirano, respectivamente. El tirano, degeneración del príncipe, y la tiranía son descritos con gran fuerza como contrapunto de lo que ha dicho sobre el príncipe auténtico: imagen de Dios en la tierra, administrador de la ley, cabeza del cuerpo social ${ }^{24}$. Dado que el tirano oprime a los súbditos, destruye la auténtica convivencia y la paz, nuestro autor sostiene que puede y debe ser eliminado. El tiranicidio no sólo es lícito, es obligatorio. Sólo excluye el veneno como método para eliminarlo: «Es justo matar a los tiranos y liberar al pueblo de Dios [...]. Respecto a la licitud de envenenar, no he leído que sea lícito por ningún derecho» ${ }^{25}$.

La ley. Las reflexiones sobre la ley están íntimamente ligadas a la misión del gobierno de los príncipes. La obra de gobierno ha de estar sometida a la ley. Ya vimos como la sujeción o no a la misma constituye la diferencia entre príncipe y tirano. La primera ley a tener en cuenta es la ley natural. Esta ley es inmutable, y toda ley positiva ha de estar supeditada a ella. Pero, para un cristiano del medievo, esta ley estaba reflejada en la Biblia. La ley divina incluye a la natural. De ahí la gran importancia que confiere Juan al Deuteronomio. Al lado de la Biblia, las leyes del Derecho Romano se consideran expresión de la ley natural. El intérprete legítimo de la ley es la autoridad eclesiástica, dado que, como escribe el historiador de la política medieval W. Ullmann: «Sólo el clero estaba calificado para pronunciarse acerca de los ingre-

20 Ladero, M. A., «Introducción» al Policraticus (citado) pp. 59-60.

21 P, V, 2, pp. 347-348; PL, 199, 540A-541A.

22 Cfr., P, VI, 21, pp. 471-473; PL, 199, 619A-620D.

23 Geymonat, L. Historia de la Filosofía y de la Ciencia, vol 1 (Antigüedad y Edad Media), Barcelona, Crítica, 1985 , p. 246.

24 Cfr. P, VIII, 17, pp. 714-715; PL, 199; 777C-778B.

25 P, VIII, 20, p. 270; PL, 199, 796B, C. 
dientes esenciales de la ley [...]. Nadie excepto el clero se hallaba capacitado para decir si la ley que se proponía estaba o no en consonancia con las exigencias de la fe» ${ }^{26}$.

Origen de la autoridad del príncipe: toda autoridad proviene de Dios, pero no a través del pueblo. En concreto el vehículo que confiere la autoridad al príncipe es la autoridad eclesiástica o espiritual ${ }^{27}$.

Poder civil y religioso (Sacerdocio-Imperio). Dada la peculiaridad del medievo, las relaciones entre estos dos poderes fue fuente constante de discusiones teóricas, y sobre todo de tensiones prácticas. La postura de Juan es clara en cuanto a la distinción, y orden jerárquico de ambos poderes. Pero, aunque el poder espiritual es superior al civil, lo que defiende el conciliador Juan es una armoniosa convivencia y colaboración. Es la gran utopía medieval ${ }^{28}$. No obstante, para Juan, los reyes están sometidos a la Iglesia, y esta es la dispensadora del poder que detentan.

Los análisis de filosofía política de Juan de Salisbury son del máximo interés, dado el momento en que realiza su actividad, convirtiéndose en un auténtico pionero de filosofía política en la Edad Media. Unas apreciaciones muy autorizadas de W. Ullmann pueden servir como colofón a lo dicho sobre la filosofía política del saresberiense: «Merece que se le preste atención por su sentido práctico, su amplitud de visión y sus conocimientos clásicos, y porque se trata de un contemporáneo de Tomás Becket y su lucha contra el rey Enrique II, enfrentamiento en que en muchos aspectos intervenían los mismos elementos básicos de la tesis hierocrática entonces en pleno desarrollo» ${ }^{29}$.

\section{LA ACTIVIDAD DOCENTE}

Dado que este trabajo está dedicado a Joaquín Lomba, destacado profesor y escritor, considero muy oportuno recoger, aunque sea telegráficamente, las reflexiones del pensador británico sobre tales tareas para finalizar la presentación de la dimensión práctica de la filosofía.

Juan no fue «magister», pero conoció a muchos maestros, unos eminentes y otros no tanto. Esto le da pie para unas reflexiones pedagógicas de palpitante actualidad en su época y, sin duda, en la nuestra. Entre los maestros más eminentes que cita están Pedro Abelardo, a quien llama «El Peripatético Palatino», y del cual fue alumno, y Bernardo de Chartres $(\uparrow 1130)$ de quien no fue alumno, con máxima probabilidad, pero sí tenía noticias abundantes de su actividad magistral. De Abelardo destaca, en especial, la claridad y el método de enseñanza. Esto que ejercía en la praxis el maestro Pedro, lo fundaba en sus reflexiones teóricas. El orden y claridad son esenciales en un buen docente. Oigamos al Peripatético Palatino: «El docente evitará todas las palabras que no enseñen (aclaren) [...]. Es señal de un talante distinguido amar lo verdadero en las palabras, no las meras palabras bellas. Una llave de oro no vale para nada si de abrir una puerta se trata, y no lo realiza» ${ }^{30}$. Sin la menor duda estas sugerencias las escuchó más de una vez el ilustre discípulo, y las asumió en su tarea de escritor, y las considera de obligado cumplimiento para todo docente, que se precie de auténtico. En cuanto a Bernardo de Chartres (el otro gran maestro citado) las alusiones frecuentes sobre su personalidad en las obras del saresberiense completan el perfil de un docente excepcional ${ }^{31}$. Pretendía formar a sus discípulos más que abrumarlos con datos y erudición. Como gramático cultivaba no sólo el estilo, sino también la conciencia moral de sus discípulos. Insistía en que el contacto con los gran-

Ullman, W., Historia del pensamiento político en la Edad Media., Tomo I, México, Jus, 1945, p. 118.

Cfr., P, IV, 3, p. 309-311; PL, 179, 516A-517B.

Cfr., P, VII, 20, pp. 574-575; PL, 179, 686B-C.

Ullmann, W., Op. Cit., p. 117.

Abelardo, P., Sic et non, Prologus; PL, 178, 1340 A-B. 
des escritores de la antigüedad clásica resultaba muy fructífero, pero no para quedarse anclados en el pasado, sino para abrirse al presente y futuro. De ahí la célebre comparación de los enanos sobre los hombros de gigantes que con tanto éxito utilizaba el insigne maestro ${ }^{32}$. Este conocido símil de los gigantes y enanos, que utilizaba el maestro Bernardo y que conocemos gracias a la información de Juan, es muy ilustrativo de la visión pedagógica de los grandes educadores del siglo XII. El presente es más rico que el pasado, pero hay que tener en cuenta las enseñanzas anteriores, si no queremos perder los logros del pretérito que condicionan y posibilitan las riquezas del presente. Por otra parte, se requiere una apertura al futuro. El porvenir que se vislumbra desde el presente es el otro polo que da sentido a la tarea educativa.

Para terminar esta alusión a los aspectos pedagógicos en las obras de nuestro autor, vamos a fijarnos en el capítulo 17 del libro II del Metalogicon cuyo título reza como sigue: «Quam perniciose doceatur et quae fuerint de generibus et speciebus opiniones modernorum» (Docencia perniciosa, y opiniones de los modernos sobre los universales). Las primeras palabras del título, como se aprecia, hacen alusión a la docencia inadecuada, de modo especial, en lo referente al problema de los universales. Por ello hace unas advertencias de tipo pedagógico sumamente interesantes. «Muchos maestros tienen una metodología de enseñanza totalmente desafortunada. Pretenden hablar de cualquier problema y del modo más abstruso, sin tener en cuenta a sus alumnos, buscando tan sólo la propia ostentación, y así no se privan de hablar de los temas más difíciles ante principiantes inexpertos que en modo alguno los entienden. Sin embargo, una pedagogía adecuada exige claridad, brevedad y sencillez, adaptándose con todo empeño a los que han de ser iniciados» («Nostri vero ad ostentationem scientiae suae sic suos instituunt auditores ut non intelligantur ab eis [...]. Sed nunc non erat his locus, cum oratio simplex, res brevis, et facilis quantum potest debeatur introducendis») ${ }^{33}$.

\section{LA TAREA DE ESCRITOR}

Juan de Salisbury no sólo escribe obras de gran valor, sino que también reflexiona sobre la tarea del escritor. Insiste en el inmenso interés y valor social del oficio de escritor, así como en la responsabilidad inherente a una labor que aporta un enorme servicio a los demás, sobre todo, a las generaciones futuras: «El que habla se expone al juicio de uno o varios que le escuchan, pero el que escribe se expone a los juicios de todos, de cualquier lugar y de cualquier época subsiguiente» ${ }^{34}$. Ya en el prólogo del libro primero del Policraticus, había dicho: «El ocio sin letras es muerte y sepultura del hombre que vive» ${ }^{35}$.

Nuestro autor, con su ejemplo, es un paradigma a seguir. En el Policraticus tiene páginas preciosas sobre la importancia y la utilidad de la tarea del escritor: «Deleitable es, en muchos aspectos, el fruto de los escritos, pero muestra sobre todo su plenitud en que, evitando la dificultad que ofrecen las distancias de tiempo y lugar, hace mutuamente presentes a los amigos y no permite la desaparición de todo aquello que es digno de ser conocido.

Pues habrían parecido las artes, se habrían perdido los diversos derechos, habrían sucumbido todas las ayudas de la fe y de toda religión y aún el mismo recto uso del lenguaje habría desaparecido, si la misericordia divina no hubiese proporcionado, para remedio de la debilidad humana, el uso de la escritura. A nadie hubieran fortalecido o preservado los ejemplos de nuestros antepasados —estímulo y fomento de la virtud-, si el solícito cuidado de los escritores y su diligencia, vencedora de la inercia, no lo hubiera transmitido a sus descendientes. 
Porque la brevedad de la vida, la rudeza de los sentidos, la torpe negligencia, el ocio inútil nos permiten saber pocas cosas, y esas mismas las perturba y arranca, continuamente, de nuestra alma el olvido, estafador de la ciencia, calamitoso y traidor enemigo de la memoria. ¿Quién hubiera conocido a los Alejandros y Césares o admirado a los estoicos y peripatéticos, si no los hubieran consignado las obras de los escritores? ¿Quién imitaría los ejemplos incitantes de los apóstoles y los profetas, si las divinas escrituras no los hubieran consagrado para la posteridad?

Los arcos triunfales sólo sirven de provecho para la gloria de los hombres ilustres, cuando sus inscripciones nos enseñan de quién son y por qué se erigieron. [...]. Porque nadie habló jamás con permanente gloria, si no es a través de los escritos propios o ajenos. Al cabo de breve tiempo, idéntica es la gloria de un asno o la de un emperador cualquiera, si su recuerdo no se prolonga con la ayuda de uno u otro escritor. ¿Cuántos y qué grandes reyes no crees que han existido, de los que nunca se habla ni se piensa? Nada, pues, más aconsejable, para los buscadores de gloria, que merecer el máximo favor de literatos y escritores. Porque los más egregios homenajes son inútiles para ellos, condenados a perpetuas tinieblas, si no brillan con la luz de la escritura. Todo favor o alabanza, conseguida de otras fuentes, es como el eco conocido de la fábula, que recibe los aplausos del teatro. Acaba cuando apenas comenzó.

Por otro lado, se recaba siempre, de los escritos, consuelo en el dolor, descanso en el trabajo, alegría en la pobreza, modestia en las riquezas y placeres. Pues el alma se libra de los vicios, y aun en las adversidades, goza de una cierta alegría, sorprendente y suave, cuando aplica el entendimiento a leer o escribir cosas útiles. No encontrarás en lo humano ocupación más útil y gozosa» ${ }^{36}$.

Estimo que estas sugerentes palabras, escritas hacia el año 1159 , no dejan de ser de la más palpitante actualidad en los albores del siglo XXI.

César Raña Dafonte

Departamento de Filosofía

Facultad de Filosofía

Campus Universitario Sur

15782 Santiago de Compostela 